\title{
Microstructure and Mechanical Properties of Ti40Nb Alloy after Severe Plastic Deformation
}

\author{
Yury P. Sharkeev ${ }^{1,2, a)}$, Anna Yu. Eroshenko ${ }^{1, b)}$, Ivan A. Glukhov ${ }^{1, c)}$, \\ Qifang $\mathrm{Zhu}^{3, \mathrm{~d})}$, and Alexey I. Tolmachev ${ }^{1, \mathrm{e})}$ \\ ${ }^{1}$ Institute of Strength Physics and Materials Science SB RAS, Tomsk, 634055, Russia \\ ${ }^{2}$ National Research Tomsk Polytechnic University, Tomsk, 634050, Russia \\ ${ }^{3}$ General Research Institute for Non-ferrous Metals, Beijing, China \\ a) Corresponding author: sharkeev@ispms.tsc.ru \\ b) eroshenko@ispms.tsc.ru \\ c) gia@ispms.tsc.ru \\ d) qiangzhu222@126.com \\ e) tolmach@ispms.tsc.ru
}

\begin{abstract}
The study presents the analysis of microstructure, phase composition and mechanical properties of $\mathrm{Ti} 40 \mathrm{Nb}$ alloy exposed to severe plastic deformation. It was shown that isothermal multi-axial forging and further multi-pass rolling intensify the formation of ultra-fine grained structure in the bulk of a billet with the average element size of $0.3 \mu \mathrm{m}$. Such ultra-fine grained structure considerably improves the alloy mechanical properties.
\end{abstract}

Keywords: severe plastic deformation, Ti40Nb, ultra-fine grained structure, phase composition, microhardness

\section{INTRODUCTION}

Today, more and more materials used for producing implants should respond to modern medical requirements. Thus, only titanium and several titanium alloys are suitable for this purpose. One of the prevailing alloys suitable for medical implants is Ti6Al4V titanium alloy, which has the required strength properties. Current medical requirements limit the preferred alloys by those containing no toxic doping elements (Al, V and others) [1]. Hence, the most preferable ones are valve metals, such as $\mathrm{Ti}, \mathrm{Zr}, \mathrm{Nb}$, and their alloys. The development of advanced implants constantly impose new requirements not only for the furthering hardening of existing materials, but also for designing new materials with low elastic modulus level. This will allow the distribution of deformation and strain at bone-implant interfaces and exclude the possible fault at the location of rigid fixation of the implant to a bone. Elastic modulus for most titanium alloys ranges from 100 to $120 \mathrm{GPa}$, while that of the dense tubular bone varies from 15 to $30 \mathrm{GPa}$ [2]. Accordingly, the development of compatible titanium alloys (for example, such alloy systems as Ti-Nb and $\mathrm{Ti}-\mathrm{Nb}-\mathrm{Zr}$ ) is a promising topic in the technology of medical materials, because the niobium-doped titanium alloy (containing about $40 \mathrm{wt} . \%$ of $\mathrm{Nb}$ ) can have the decreased elastic modulus ranging from 55 to $60 \mathrm{MPa}[1,2]$.

Severe plastic deformation methods [3-7] enable the production of nanostructured and ultra-fine grained semifinished billets with significantly improved mechanical properties in comparison to their coarse-grained analogues. The nanostructured state in metals and alloys is usually attained by combining two or more different severe plastic deformation methods, for example, isothermal multi-axial forging or equal-channel angular pressing and rolling [3].

The aim of the work was to investigate the microstructure, phase composition and mechanical properties of $\mathrm{Ti} 40 \mathrm{Nb}$ alloy exposed to severe plastic deformation. 


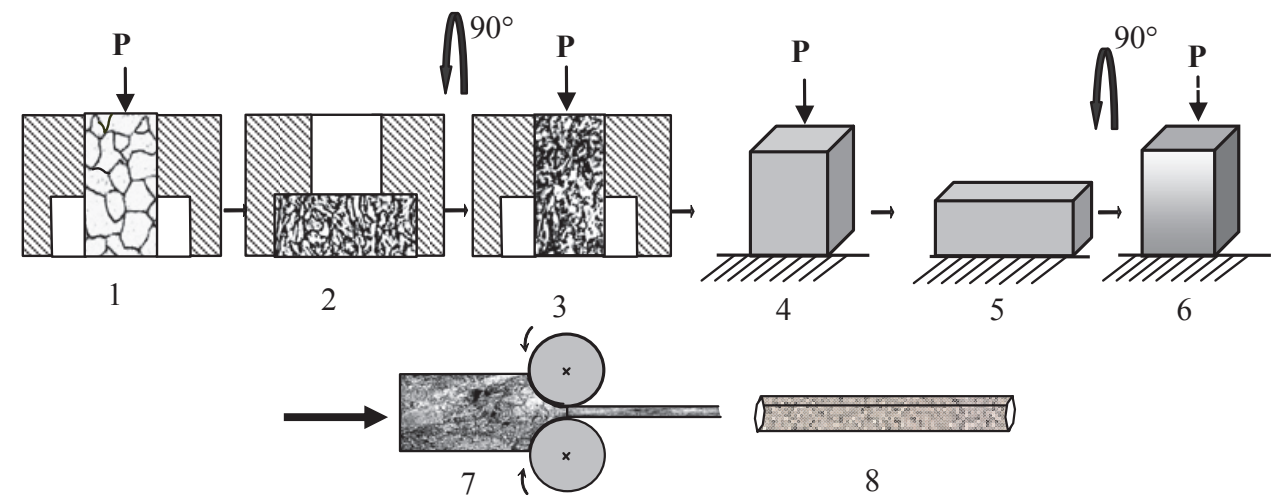

FIGURE 1. Isothermal multi-axial forging scheme and further rolling of samples: 1 -initial sample (arrow shows the direction of the imposed load during compaction in a pressing mold); 2 - the sample after the first compaction; 3 - pressing repetition with the rotation of deformation axis in pressing mold; 4-sample before free isothermal multi-axial forging (arrow shows the direction of the imposed load during compaction out of the pressing mold); 5 - the sample after the first free isothermal multiaxial forging; 6-isothermal multi-axial forging of samples out of a press-mold; 7-rolling using grooved rolls; 8-sample bar after rolling

\section{SPECIMEN AND EXPERIMENTAL PROCEDURES}

Initial billets were made from Ti40Nb alloy. The cast was produced by the electric arc melting. Samples of $14 \times 16 \times 32 \mathrm{~mm}$ size were cut from a remelted cast and exposed to a combined 2-stage severe plastic deformation. Prior to deformation, titanium alloy samples were annealed at $1100^{\circ} \mathrm{C}$ for 1 hour in argon and then quenched by water.

During the first stage, the samples were deformed by isothermal multi-axial forging comprising three cycles $[6$, 7]. Each cycle included three compactions at constant temperature. When going over the next compaction cycle the temperature of the samples was gradually decreased down to $500^{\circ} \mathrm{C}-400^{\circ} \mathrm{C}$. After every compaction, the sample was rotated at $90^{\circ}$, while the deformation size of the sample in each compaction was not more than $40 \%$. There were nine compactions performed in total. For the purpose of a more effective grain refinement, the samples were placed into a pressing mold during the first two compactions (Fig. 1), while during the following seven compactions the samples were deformed without the pressing mold. The total logarithmic deformation value was 6.12 . Total deformation value was calculated as the sum of natural logarithms of the initial and final sample thickness ratio at each step of deformation. After nine compactions, the titanium alloy samples had parallelepiped shape with the dimensions of $16 \times 18 \times 20 \mathrm{~mm}$.

During the second stage, the samples after multi-pass rolling deformed at room temperature in grooved rolls reaching the deformation value of 1.2 , the rolling speed was $10 \mathrm{~m} / \mathrm{min}$. Rolling was conducted up to reaching the finite deformation at the shrinkage of $2 \%-3 \%$ and the total number of passes of 70 . Eventually, the rolling bars with the dimensions of $6 \times 6 \times 160 \mathrm{~mm}$ were obtained. To reduce internal stress and elasticity, the bars were annealed at $300^{\circ} \mathrm{C}$ for 1 hour in argon atmosphere.

Sample microstructure was investigated by optical microscopy (Carl Zeiss Axio Observer) and transmission electronic microscopy (JEM-2100, Investigation was conducted using the equipment of "NANOTECH" Common Use Center of ISPMS SB RAS (CPS TRC SB RAS)). The average size of structure elements (grains, subgrains, fragments) was calculated by a linear secant method [8]. Microstructure investigation and microhardness testing of initial samples and samples subjected to isothermal multi-axial forging and rolling were carried out by analyzing the cross-section of billets, the former being perpendicular to the last compaction axis. The Vickers microhardness was measured using Duramin 5 microhardness analyzer. X-ray diffraction was performed using DRON-7 diffractometer ${ }^{2}$. The measurements of intensity profiles were carried out by monochromatic $\mathrm{CoK}_{\alpha}$-radiation.

Figure 2a shows the microstructure of annealed titanium alloy. In the alloy structure, polyhedral grain boundaries of primary $\beta$-phase with body-centered cubic lattice, pitted by dendritic segregation are preserved (Fig. 2(a)). The size of polyhedral $\beta$-Ti-based grains are within the range of $400-800 \mu \mathrm{m}$. 


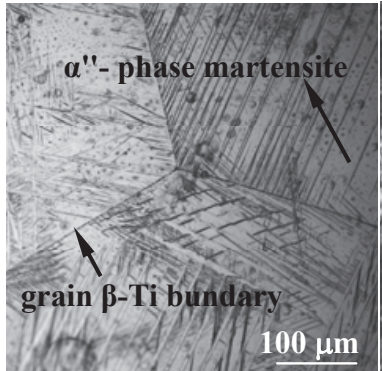

(a)

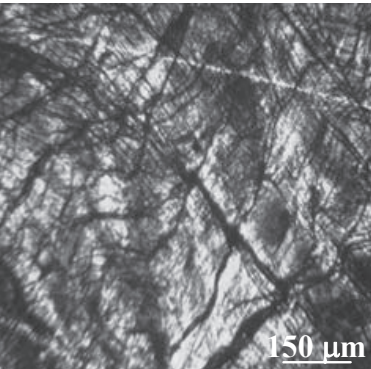

(b)

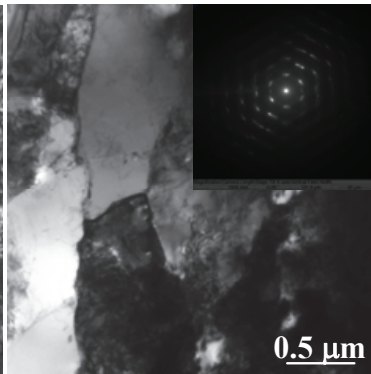

(c)

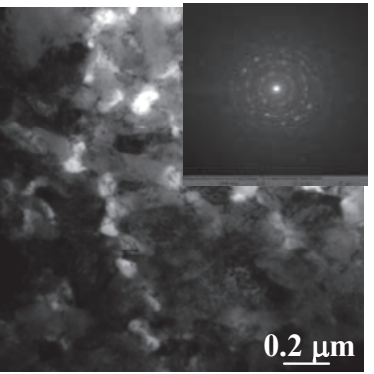

(d)

FIGURE 2. Optical (a, b) and bright-field transmission electron microscope images (c, d) of alloy microstructure: (a) initial state; (b and c) are images of the sample after isothermal multi-axial forging; (d) sample after isothermal multi-axial forging and rolling

\section{RESULTS AND DISCUSSIONS}

The $\beta$-phase grain volume includes acicular inclusions that are characteristic for metastable orthorhombic martensite $\alpha^{\prime \prime}$-phase [9]. The formation of such a structure after annealing is characteristic for titanium-based alloys containing from 30 to $40 \mathrm{wt} . \%$ of $\mathrm{Nb}$ [11]. Average alloy microhardness value after annealing amounted $1730 \mathrm{MPa}$.

Figure 2(b) shows the microstructure image of the investigated alloy after isothermal multi-axial forging in cross-section of billet. Isothermal multi-axial forging resulted in the fragmentation of the structure due to the formation of numerous localized deformation bands. Obviously, this behavior is associated with the fact that the prevailing deformation mechanism at $500^{\circ} \mathrm{C}-400^{\circ} \mathrm{C}$ is sliding and the formation of localized shear band. Transmission electron microscopy images of the microstructure show that the $\beta$-Ti grain is elongated along the direction of the deformation axis (Fig. 2(c)). The average grain and subgrain size reduced to its initial state down to $0.8 \pm 0.2 \mu \mathrm{m}$. The subgrains are observed inside the grain itself, the boundaries of which are barely discernible. Existing extinction contours show the evidence of high residual stress level in the material after deformation. The microhardness value of the billets after isothermal multi-axial forging increases up to $2300 \mathrm{MPa}$ in comparison to that in the initial state.

Figure 2(d) shows the microstructure of titanium alloy in cross section of billet after isothermal multi-axial forging in combination with rolling by grooved rolls. One can see that the structure elements are elongated in the direction of rolling and the structure includes the accumulation of dislocations with high density. Selected area diffraction pattern has a quasi-ring shape, indicating the existence of large-angle boundaries, while the azimuth diffusion indicates a high internal stress level. It should be noted that another characteristic feature of the microdiffraction pattern is the existence of striated reflections with maximum intensity and distinct symmetry that indicate the texture. The average structure element size is $0.3 \mu \mathrm{m}$, which corresponds to the ultra-fine grained state

(a)

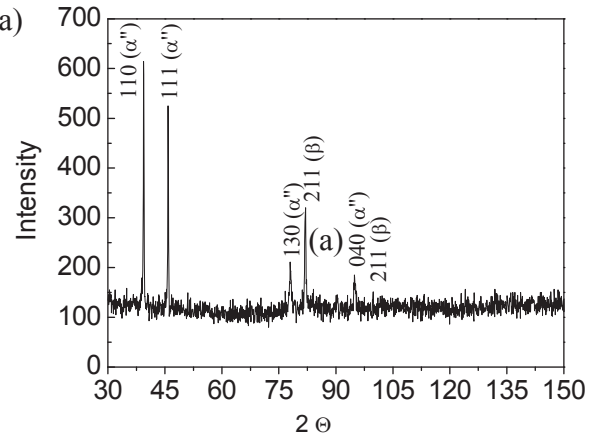

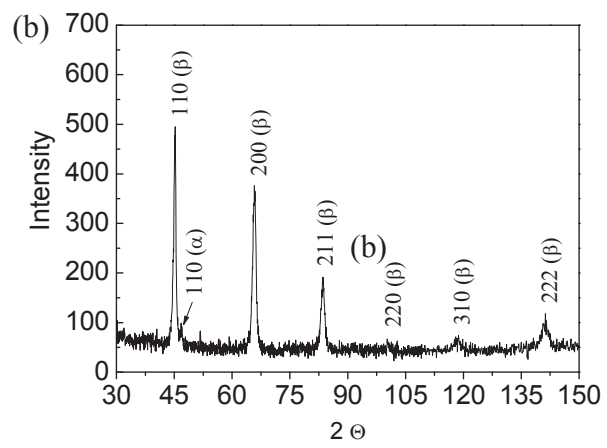

FIGURE 3. X-ray diffractograms of the alloy (a) after annealing and (b) after isothermal multi-axial forging and consequent rolling 
The selected area diffraction pattern shows not only reflections of high intensity from $\beta$-Ti-based solid solution, but also reflections of low intensity from $\alpha$-Ti. Metastable martensite phase of $\alpha^{\prime \prime}$-Ti solid solution could not be identified. In this case, it is obvious that during severe plastic deformation $\alpha^{\prime \prime}$-martensite phase is transformed as follows: $\alpha^{\prime \prime} \rightarrow \beta+\alpha[9,10]$.

$\mathrm{X}$-ray diffractograms of the annealed alloy subjected to isothemral multi-axial forging with consequent rolling are presented in Fig. 3.

Reflections of metastable martensite $\alpha^{\prime \prime}$-phase and $\beta$-Ti-phase demonstrate the annealed state (Fig. 3(a)). During the isothermal multi-axial forging and rolling the metastable $\alpha^{\prime \prime}$-phase changes to stable $\beta$-phase solid solution (Fig. 3(b)). Additional rolling deformation increases the microhardness level up to $2800 \mathrm{MPa}$.

\section{CONCLUSION}

Combined severe plastic deformation method and multi-stage isothermal multi-axial forging with consequent multi-pass rolling, allows forming an ultra-fine grained structure with the average size of element structure of $0.3 \mu \mathrm{m}$ in the bulk of Ti40 Nb alloy. Metastable $\alpha^{\prime \prime}$-phase during severe plastic deformation transforms into stable $\beta$ phase of titanium solid solution and its $\alpha$-phase. As a result of severe plastic deformation, the formed ultrafinegrained structure provides the increased microhardness of up to $2800 \mathrm{MPa}$ which, in turn, is approximately 1.6 times more than that of the initial specimen $(1730 \mathrm{MPa})$.

\section{ACKNOWLEDGEMENTS}

The investigation was supported by the RAS Presidium program for fundamental research, project 8.21 and the Program for fundamental research of SB RAS for 2013-2016, project No. III.23.2.2.

\section{REFERENCES}

1. M. A.-H. Gepreel and M. Niinomi, J. Mech. Behavior Biomed. Mater. 20, 407 (2013).

2. M. Niinomi, M. Nakai, and J. Hieda, Acta Biomater. 8, 888 (2012).

3. R. Z. Valiev, J. Mater. Sci. 42, 1483 (2007).

4. V. M Segal, Mater. Sci. Eng. 271(1), 322 (1999).

5. G. A. Salishchev, R. G. Zaripova, R. M. Galeev, and O. P. Valiakhmetov, Nanostruct. Mater. 6(5), 913 (1995).

6. Yu. P. Sharkeev, E. V. Legostaeva, A. Yu. Eroshenko, I. A. Khlusov, and O. A. Kashin, Compos. Interfaces 16, 535 (2009).

7. A. D. Bratchikov, Yu. P. Sharkeev, Yu. R. Kolobov, A. Yu. Eroshenko, and M. P. Kalashnikov, RF Patent 2315117 (2008).

8. ASTM E1382-97 Standard Test Methods for Determining Average Grain Size Using Semiautomatic and Automatic Image Analysis (2010).

9. Y. Mantani and M. Tajima, Mater. Sci. Eng. A 438-440, 315 (2006).

10. H. Y. Kim, Y. Ikehara, J. I. Kim, H. Yosoda, and S. Miyazaaki, Acta Mater. 54, 2419 (2006). 